\title{
INCLUSÃO ESCOLAR: CONCEPÇÕES DE PROFESSORES E PRÁTICAS EDUCATIVAS
}

\author{
SCHOOL INCLUSION: CONCEPTIONS OF TEACHERS AND EDUCATIONAL PRACTICES \\ INCLUSIÓN ESCOLAR: CONCEPCIONES DE LOS PROFESORES Y LAS PRÁCTICAS EDUCATIVAS
}

\author{
Ana Paula Medeiros* \\ Sylvia Domingos Barrera ${ }^{* *}$
}

\begin{abstract}
RESUMO
Este estudo buscou investigar as concepções de professores envolvidos com a inclusão escolar, conhecer o andamento de aulas em que há alunos de inclusão e como o tema aparece nos Projetos Político-Pedagógicos (PPP). A pesquisa ocorreu em uma escola pública e duas particulares. Foram entrevistados 13 educadores, observadas três alunos de inclusão e analisados dois PPP. Constatou-se que os professores percebem uma dicotomia entre a teoria e a prática da inclusão, embora o discurso seja majoritariamente favorável ao tema. Há pouca adaptação das escolas e a aprendizagem é falha. Professores de escolas particulares recebem maior incentivo de formação continuada, e os da escola pública desejam maior apoio. Os PPP não abordam o tema. A inclusão escolar está distante dos objetivos.
\end{abstract}

Palavras-chave: Inclusão escolar. Necessidades educativas especiais. Professores.

\begin{abstract}
This study aimed to investigate the conceptions from teachers involved with school inclusion, the knowledge of class practices where there are inclusion students and how the issue is approached in the political-pedagogical projects (PPP). The research took place in a public school and in two private ones. Thirteen teachers were interviewed, three inclusion students were observed and two PPP were analyzed. The results show that teachers perceive a dichotomy between the theory and the practice concerning inclusion, in spite of the fact that the discourse is largely favorable to the matter. There are few adaptations on the school side and the teaching is faulty. Private school teachers receive greater encouragement prone to continued education and those from public school long for more support. The PPPs do not approach the issue. School inclusion is far from their objectives.
\end{abstract}

\footnotetext{
Texto recebido em 29 de novembro de 2014 e aprovado para publicação em 13 de novembro de 2015.

* Mestre pela Faculdade de Filosofia, Ciências e Letras de Ribeirão Preto (Universidade de São Paulo), psicóloga. E-mail: paulla_ medeiros@hotmail.com

* Professora doutora no Departamento de Psicologia da Faculdade de Filosofia, Ciência e Letras de Ribeirão Preto (Universidade de São Paulo). E-mail: sdbarrera@ffclrp.usp.br
} 
Keywords: School inclusion. Special educative requirements. Teachers.

\section{RESUMEN}

Este estudio procuró investigar las concepciones de los profesores que participan en la inclusión escolar, conocer el progreso de las clases en las que hay alumnos de la inclusión y la forma en que el tema aparece en los proyectos político-pedagógicos (PPP). La investigación se llevó a cabo en una escuela pública y dos privadas. Entrevistamos a 13 educadores, observamos tres estudiantes de inclusión y analizamos dos PPP. Se encontró que los docentes perciben una dicotomía entre la teoría y la práctica de la inclusión, aunque el discurso fue ampliamente favorable al tema. Hay poca adaptación de las escuelas y falla el aprendizaje. Los maestros de escuelas privadas reciben mayor estímulo de educación continuada y los de la escuela pública quieren más apoyo. Los PPP no abordan el tema. La inclusión escolar está lejos de los objetivos.

Palabras clave: Inclusión escolar. Necesidades educativas especiales. Profesores.

\section{INTRODUÇÃO}

inclusão escolar é um processo cercado de desafios. Nesse sentido, a pesquisa $A$ pode oferecer subsídios para compreender melhor como esse processo 1 vem sendo implantado, a fim de colaborar para a definição de políticas públicas educacionais. O termo "inclusão" passou a ser empregado na literatura a partir da década de 1980 e defende a ideia de que a sociedade precisa respeitar as pessoas com Necessidades Especiais (NEE) e organizar-se para recebê-las (Aranha, 2001).

Muitos documentos foram elaborados para embasar a inclusão escolar, sendo o mais importante a Declaração de Salamanca (UNESCO, 1994), que reconhece que os alunos com NEE devem ser incluídos e ter suas necessidades atendidas em escolas regulares, definindo quais são as responsabilidades das partes envolvidas, como o Estado, a escola e a comunidade. É necessário que as escolas utilizem as legislações como ponto de partida e se mobilizem para executar as mudanças precisas. Segundo Silva (2013), a adaptação física do prédio não é suficiente para que a inclusão ocorra, sendo fundamental a mudança na organização escolar.

A inclusão envolve várias questôes que precisam ser discutidas para que sua implantação não consista apenas na matrícula desses alunos na escola regular (Silva, 2011). A proposta da inclusão é fundamentada na ideia de que todos os alunos precisam ter acesso a ensino de qualidade em escola regular, 
independentemente de suas características ou limitaçôes (Lei no 9.393,1996). A inclusão deve proporcionar meios de aprendizagem, de socialização e preparar os alunos para a inserção na sociedade (Pletsch, 2009). Algumas pesquisas têm verificado a exclusão desses alunos da escola, concluindo que eles passam a maior parte do tempo sozinhos (Batista \& Enumo, 2004). Mesmo assim, a socialização, que não é o principal objetivo da inclusão, é considerada o maior, ou único, ganho do processo (Oliveira \& Miranda, 2007).

A reorganização da escola demandada pelo conceito de inclusão deve ser iniciada a partir da construção de um novo projeto político-pedagógico que contemple a diversidade humana e a mudança de paradigmas (Melo \& Martins, 2007). Esse documento deve envolver a gestão e o corpo docente, de forma que o currículo deve ser formulado com flexibilidade e considerar as características e necessidades de todos os alunos (Costa, 2011; Vianna, Gomes, \& Garcia, 2013). Durante o ano, a escola deve avaliar o seu trabalho, os avanços e dificuldades dos alunos, definir novas metas e promover estratégias de atuação (Machado, Fontes, Assumpção, \& Glat, 2006).

As atitudes positivas dos envolvidos no processo beneficiam a inclusão dos alunos. Os professores devem saber que o aluno com NEE tem as suas potencialidades, que precisam ser trabalhadas. A equipe gestora deve ser integrada à equipe, principalmente pela possibilidade de estabelecer um vínculo entre escola e órgãos governamentais (Oliveira, Santos, Rodrigues, \& Vianna, 2011). A instituição precisa oferecer suporte para que os professores possam diferenciar suas práticas pedagógicas (Fiório \& Almeida, 2013). A pesquisa sobre inclusão escolar torna-se essencial para conhecer o andamento do processo e possibilitar estratégias de trabalho.

\section{OBJETIVOS}

O objetivo geral da pesquisa foi analisar o andamento do processo de inclusão de alunos com NEE em instituições escolares. Como objetivos específicos, elencamos:

a) conhecer a perspectiva de professores envolvidos com o processo de inclusão escolar;

b) analisar as práticas das aulas em que há alunos com NEE;

c) analisar como o tema da inclusão aparece nos Projetos Político-Pedagógicos (PPP) das escolas. 


\section{MÉTODO}

A pesquisa seguiu um delineamento quali-quantitativo. Foi realizada em três escolas do interior paulista que tinham ao menos um aluno com NEE matriculado havia mais de um ano. Diversas escolas foram contatadas, mas apenas três aceitaram a participação. A escola A é uma escola pública estadual, com 591 alunos e atende ao ensino fundamental II e ao ensino médio. A escola B é particular e oferece educação infantil e ensino fundamental para 586 alunos. A escola C é particular e oferece de educação infantil a ensino médio, com 935 alunos.

Todos os professores e coordenadores envolvidos no processo de inclusão escolar dessas escolas foram convidados a participar da pesquisa. Realizaram-se 13 entrevistas, sendo $11 \mathrm{com}$ professores e $2 \mathrm{com}$ coordenadoras pedagógicas, destes profissionais, 6 trabalhavam na escola A, 3 na escola B e 4 na escola C. Os entrevistados lecionavam para números variados de alunos com NEE: 6 deles tinham um aluno, e os demais variavam entre 2 e 10 alunos. Nenhum dos professores lecionava para mais de um aluno com NEE na mesma sala. Majoritariamente, os alunos com NEE dessas escolas apresentam síndrome de Down, havendo outros com paralisia cerebral e um aluno diagnosticado com síndrome de Asperger.

A pesquisa contou com observações em salas de aula de três alunos com NEE. Foram observados apenas os alunos cujos pais autorizaram a realização dessa atividade. A observação em sala de aula também foi autorizada pelos professores. O primeiro aluno será chamado de Pedro, tem 20 anos e estuda na escola A. Ele tem paralisia cerebral de grau grave e está no $1^{\circ}$ ano do ensino médio. Artur foi diagnosticado com síndrome de Asperger. Ele tem 20 anos, estuda na escola $\mathrm{C}$ e está no $2^{\circ}$ ano do ensino médio. A terceira aluna será chamada de Iara, tem 15 anos, tem síndrome de Down, estuda na escola $C$ e está no $7^{\circ}$ ano do ensino fundamental.

\subsection{Procedimento}

As entrevistas seguiram roteiro semiestruturado, foram audiogravadas e transcritas. Todos os nomes foram substituídos. Foram realizadas observações em sala de aula nas escolas $\mathrm{A}$ e $\mathrm{C}$, pois a escola $\mathrm{B}$ não autorizou a observação. Os dados obtidos foram transcritos em diário de campo. Buscou-se ler e analisar os PPP das escolas, a fim de verificar como o tema da inclusão escolar é contemplado, porém a escola $\mathrm{B}$ não apresentou seu PPP. Os dados obtidos com as entrevistas foram submetidos a análise de conteúdo Bogdan e Biklen (2000). Os obtidos com as observações em sala de aula foram transcritos em 
diário de campo, sendo essas informações e aquelas obtidas da análise dos PPP consideradas em triangulação com os dados das entrevistas, a fim de propiciar uma visão integrada da questão da inclusão a partir de diferentes perspectivas.

Quanto aos aspectos éticos, os entrevistados e os pais dos alunos observados assinaram o termo de consentimento livre e esclarecido. O projeto foi aprovado pelo Comitê de Ética em Pesquisa da Universidade à qual a pesquisa está ligada.

\section{RESULTADOS}

Os dados obtidos nas entrevistas foram organizados em categorias que expressassem da melhor maneira as concepçóes e a opinião dos professores sobre o tema. Os dados de observação em sala de aula foram transcritos e analisados qualitativamente, para evidenciar a maneira como a inclusão vinha ocorrendo, na prática, nas diferentes escolas. A leitura dos PPP buscou identificar a forma como o tema estava (ou não) inserido nos documentos escolares, além de procurar abordar outros pontos relevantes, como o trabalho com a diversidade e a avaliação dos alunos.

\subsection{Entrevistas}

Foram organizadas 13 categorias, conforme as temáticas enfocadas nas questões das entrevistas e no conteúdo das respostas obtidas. As respostas relacionadas a cada categoria foram agrupadas em subcategorias, as quais foram quantificadas, o que permitiu uma comparação, de caráter exploratório, entre as respostas dos professores da rede pública e particular, a fim de identificar possíveis diferenças e semelhanças sobre o andamento do processo.

Na primeira categoria (opinião sobre a inclusão), foi observada uma diferença entre as respostas dos professores das escolas particulares e da pública. Na pública, predominaram respostas que enfatizavam a "dicotomia entre teoria e prática, com críticas à forma como tem sido implantada". As respostas mais frequentes dos professores das escolas particulares se dividiram entre "totalmente favorável" e "favorável com ressalvas". Como exemplos, pode-se citar a fala de Solange (escola pública): "Eu acho que a inclusão escolar não funciona, até funcionaria se saísse do papel”. Já a professora Amanda (escola particular) disse: “Eu sou a maior defensora da inclusão! Acho que o professor é capaz de conseguir fazer esse projeto funcionar".

Para a categoria 2 (sentimentos despertados pela notícia de que teria alunos com NEE), a subcategoria "aponta sentimentos ruins, sobretudo preocupação e nervosismo" englobou a maioria das respostas de todos os participantes, como 
expressou pela professora Vanessa (escola pública): "Eu fiquei muito nervosa. Não sabia como lidar com esse aluno”.

$\mathrm{Na}$ categoria 3 (relação do aluno com NEE com os demais alunos), duas foram as subcategorias mais frequentes: "vê a relação como satisfatória e que o aluno tem vários amigos na sala de aula" e "acredita que o aluno tem apenas alguns amigos e sofre preconceitos ou é excluído", não havendo diferença entre as escolas particulares e a escola pública. Já na categoria 4 (avaliação dos alunos com NEE), a subcategoria que mais abrangeu as respostas dos professores da escola pública foi "uma mesma nota é dada ao aluno em todas as disciplinas". Nas escolas particulares, predominou a subcategoria "a avaliação é diferenciada e ocorre de acordo com os avanços dos alunos”. Apesar de essa avaliação ser considerada mais pertinente, é importante destacar que houve uma diferenciação quanto aos alunos sem NEE, uma vez que estes são avaliados por métodos tradicionais, como trabalhos e provas.

$\mathrm{Na}$ categoria 5 (o que/como faz para ajudar os alunos com NEE), duas subcategorias foram mais frequentes, sendo que a subcategoria "estudando muito e estando disposta a trabalhar com o aluno de forma geral" foi a mais frequente nas escolas particulares e a subcategoria "desempenha atividades específicas com o aluno" foi a mais prevalente na escola pública. A primeira das subcategorias foi expressa pela fala da professora Amanda (escola particular): "Preciso estar disposta a ensinar esse aluno, sempre estudando muito". A segunda subcategoria foi representada pela fala de Catarina (escola particular): "Copiando ou digitando textos".

A categoria 6 (o que poderia ser feito para melhorar a educação oferecida a esses alunos) apresentou diferenças entre os professores das escolas particulares e pública: os primeiros apontaram para a necessidade de um melhor preparo dos professores, e os segundos sugeriram a presença de pessoal qualificado para esse trabalho. Enquanto os primeiros entenderam que precisavam se qualificar, os segundos esperavam que a escola recebesse outros profissionais já com essa formação. Na categoria 7 ("ganhos e perdas do processo de inclusão"), a subcategoria "têm ganhos em todos os campos, mas até certo ponto" foi a mais presente nas escolas particulares. $\mathrm{Na}$ escola pública, as respostas se dividiram entre as subcategorias "ganham na socialização e na aquisição de conhecimentos" e "ganham na socialização e perdem na aprendizagem".

$\mathrm{Na}$ categoria 8 (contato teórico com o tema da inclusão), a subcategoria "não teve contato com o tema" abrangeu todas as respostas dos professores da escola pública. Nas escolas particulares, os professores se dividiram entre "teve contato durante a graduação ou pós-graduação" e "teve contato durante cursos 
extracurriculares". A primeira subcategoria foi declarada pela professora Solange (escola pública): "Nunca tive nada sobre o tema na minha graduação e, na pós, foi apenas uma pincelada". Na categoria 9 ("avanços ou regressôes dos alunos com NEE sob o regime de inclusão"), a subcategoria "o aluno teve avanços em todos os âmbitos" abrangeu a maioria das respostas dos professores da escola pública. Os professores das escolas particulares se dividiram entre esta e "o aluno teve avanços, mas poderia ter mais em uma escola especializada", afirmação que indicou que os próprios professores percebiam que a escola não oferecia ao aluno tanta qualidade no ensino quanto ele necessitaria.

A categoria 10 (papel do professor e coordenador junto aos alunos com NEE) foi a que mais apresentou variedade de respostas, com duas subcategorias mais relevantes: "dar suporte para o aluno aprender, dedicando-se para que ocorra a aprendizagem" e "outras ideias", que abarcou a variedade de respostas dadas com relação ao tema. A categoria 11 (adaptações feitas pela escola para receber os alunos com NEE) teve diversidade nas respostas, e a subcategoria mais frequente foi "a escola não teve e não precisa de adaptações". Na escola pública, esse tipo de respostas foi acompanhado da subcategoria "a escola não teve adaptações, mas deveria ter". Na escola particular, esteve presente "adaptação de banheiros e maior preparo dos professores".

$\mathrm{Na}$ categoria 12 (avaliação da própria experiência com a inclusão), a maioria dos entrevistados apresentou respostas em que "a experiência é avaliada como muito boa”. Para os professores da escola pública essa subcategoria foi tão prevalente quanto "a experiência é avaliada como boa, mas outras coisas deveriam ser feitas". A categoria 13 (maior dificuldade encontrada) teve a subcategoria "a falta de conhecimento sobre o assunto" como mais frequente. A escola pública dividiu essa subcategoria com "falta de apoio do Estado e de outros integrantes da equipe", sendo representada pela fala de Vanessa (escola pública): "A maior dificuldade é a falta de empenho dos outros professores e da escola, que trata o aluno como se ele não tivesse aqui".

\subsection{Observações em contexto escolar}

As observações do aluno Artur (escola particular) foram realizadas no intervalo entre as aulas (20 minutos) e em duas aulas de História. Essa disciplina foi escolhida devido à disponibilidade da professora. $\mathrm{O}$ aluno tinha dificuldades cognitivas, na fala e escrita. Artur tinha um acompanhante, que o auxiliava nas tarefas, permanecia junto a ele nas aulas, ajudava-o a copiar os conteúdos e explicava as matérias. Estudava naquela escola havia seis anos. Foi a escola quem apontou para os pais do aluno a necessidade do acompanhante, os quais 
acataram a ideia, contrataram-no e pagavam suas despesas. Segundo uma das professoras, ele apresentava avanços no decorrer do tempo, mas tinha algumas dificuldades.

Durante a aula de História, Artur permaneceu em silêncio ao longo da explicação da professora. Quando esta pediu aos alunos que fizessem os exercícios da apostila, Artur realizou-os com o ajudante, que explicava as atividades, ouvia as suas respostas e discutia com ele, além de escrevê-las na apostila. Ao fim dos exercícios, Artur foi um dos alunos chamados a responder a uma questão. Embora aparentasse um pouco de nervosismo, o fez corretamente.

No intervalo, Artur se sentou em uma cadeira próxima à sala dos professores. Ele permaneceu sozinho, até que a pesquisadora se aproximou e iniciou uma conversa informal: ele contou que ficava sentado naquele local por não gostar do barulho dos alunos, da maneira como eles se tratavam e da sujeira que faziam. Falou que o seu acompanhante passava o intervalo na sala dos professores e que ele se sentia mais seguro estando por perto. Artur disse que gostava da escola, mas tinha dificuldades em algumas matérias. Disse que não gostava muito dos colegas, pois a maioria colocava apelidos nele e não o tratava bem, mas que era muito bom estar no ambiente da escola.

O aluno Pedro (escola pública) foi observado em sala de aula, entrada e intervalo da escola. Foram acompanhadas cinco aulas, sendo duas de Geografia, duas de Artes e uma de Matemática. Esse aluno utilizava cadeira de rodas, não conseguia ler e escrever, mas identificava a maioria das letras e conseguia digitálas. Ele estudava na escola desde a sétima série, já tendo estudado em uma escola especial e depois em uma regular. A sua mãe o acompanhava diariamente para a entrada, intervalo e saída. Em sala de aula, o aluno se sentava em uma carteira adaptada, que se encaixava com a cadeira de rodas. Essa carteira chegou à escola em 2009; antes, o aluno utilizava uma mesa.

No primeiro dia de observação, na aula de Geografia, a professora aplicou prova aos alunos, mas o Pedro não a recebeu, sendo essa prática rotineira dos professores, por entenderem que o aluno não era capaz de compreender a avaliação. Ele ficou sem atividade por um determinado tempo, e a professora conversou com ele por alguns minutos. A professora pediu que a pesquisadora ficasse com o aluno, enquanto ela corrigia as provas. Nesse momento, ele contou para a pesquisadora que não recebia as apostilas da escola, mas que gostaria de tê-las. Disse que gostava de pintar e que a coordenadora da escola estava the ensinando a usar o computador. Disse que se sentia muito sozinho e que queria aprender a escrever. 
Nas observações, o aluno pediu para desenhar e foi dado material a ele, que fez vários desenhos e perguntou a opinião da pesquisadora. $\mathrm{O}$ aluno pedia que esta escrevesse, copiando o escrito com auxílio. Nas aulas de Artes, o aluno se envolvia com atividades de desenho e jogo de réguas. Pôde-se perceber, nessa aula, uma melhor interação do aluno, visto que a classe sentava em grupos e tinha maior liberdade para conversar. Durante a aula de Matemática, o aluno fica mais irritado, alegando que não entendia o conteúdo e que não sabia fazer contas.

Durante a entrada dos alunos, a mãe do Pedro ficava com ele o tempo todo. Ao bater o sinal, ela o levava até a sala e o acomodava na carteira. Quando o intervalo iniciava, a mãe retirava o aluno da sala e dava lanche em sua boca. Nesses momentos, o aluno pouco interagia com seus colegas, sendo que várias meninas ficavam junto dele para conversar com sua mãe. A frequência do aluno na escola era boa, sendo que Pedro faltava apenas quando está chovendo ou quando estava muito cansado. Ele disse que gostava de ir à escola, mas que estava cansando de não ter atividades.

Iara (escola particular) foi observada em duas aulas de Educação Física, sendo uma na sala de aula e outra no pátio, em ensaio de dança. Ela se movimentava sem dificuldades, mas apresentava comprometimento na fala, leitura e escrita. Iara frequentava o $7^{\circ}$ ano da escola e estudava na instituição desde os 3 anos. De acordo com a professora, a aluna se comunicava bem, obteve avanços e adquiriu parte do conteúdo ensinado. Os pais de Iara eram muito participativos e acompanhavam o andamento da filha. A professora informou que eles pediram para que a filha refizesse algumas séries, para se apropriar mais do conteúdo, solicitação acatada pela escola.

$\mathrm{Na}$ observação em sala de aula, pôde-se perceber que a aluna participou de todas as atividades. Como haviam voltado do intervalo, a professora estipulou alguns minutos para que eles fossem escovar os dentes, tarefa que a estudante desempenhou sozinha. Os alunos voltaram para a sala de aula, e a professora passou uma música para eles, que deveria ser cantada. A aluna cantou, fez gestos parecidos com os dos colegas e depois se levantou e andou pela sala. Sentou-se no chão e mexeu na mochila de uma colega. Após isso, a professora ficou na porta da sala de aula, conversando com os pais de um aluno. Nesse tempo, os alunos conversavam e brincavam, e Iara conversava em alguns momentos e ficava quieta em outros. Em outras situações, a aluna conversava e cantava sozinha, e em voz alta.

$\mathrm{Na}$ aula em que ocorreu o ensaio da festa junina, os alunos estavam bastante agitados. A professora pediu que cada um ficasse ao lado de seu par. A aluna 
foi até o seu par, e eles dançaram, conforme a coreografia. Iara muitas vezes se distraía, saindo do espaço da dança ou ficando parada. O aluno que era seu par muitas vezes a chamava de volta, demonstrando paciência com a colega. Outros alunos também falavam para ela dançar e a elogiavam, dizendo que ela estava dançando muito bem, comportamento que a professora sempre reforçava. Pôde-se perceber que a professora tratava Iara de maneira muito parecida com os outros alunos.

\subsection{Projeto político-pedagógico}

Foram analisados os PPP de duas escolas, visto que a escola B não aceitou disponibilizar o PPP para leitura, alegando que este estava em reformulação. O fato de a escola B não querer mostrar o PPP talvez indique o reconhecimento de que esse documento estava incompleto ou de que as estratégias contidas nele não estavam sendo implementadas, sobretudo com respeito à inclusão escolar. O PPP da escola A (escola pública) não abrangia diretamente o tema da inclusão. Em termos de ambiente físico, ressaltou que a escola não tinha banheiro adaptado para atender alunos com NEE. No âmbito pedagógico, uma questão trazida pelo PPP e que estava relacionada à inclusão escolar era o tema da avaliação. De acordo com o documento, a avaliação devia ser contínua, considerando as dificuldades e avanços de cada um. A escola colocava como responsabilidade do professor promover estratégias de intervenção para sanar as dificuldades, fazendo com que o aluno aprendesse e estivesse interessado nos estudos.

O PPP da escola C (particular) esclarecia que tinha como objetivos os mesmos presentes na Lei de Diretrizes e Bases da Educação (Lei no 9.393,1996). Quanto à avaliação, foi dito que esta devia ser diagnóstica, contínua, quantitativa e qualitativa, com critérios claros e de conhecimento dos alunos. A avaliação não devia ser generalizada, devendo ser adaptada aos diferentes alunos. De acordo com o documento, a escola devia investir como uma de suas prioridades no aprimoramento do corpo docente, oferecendo oportunidades para que este se reciclasse, mantendo uma formação continuada. A escola era responsável por oferecer cursos e palestras aos professores, bem como apoio para a participação destes em cursos externos. Apesar de não trazer o tema inclusão escolar de forma explícita, havia um tópico no PPP da escola denominado "Processo de integração do aluno na escola". Esse tópico explorava a ideia de que todos os alunos deviam ser integrados no ambiente da escola, independentemente de seus problemas afetivos, sociais, de saúde e de aprendizagem. Para que isso ocorresse, destacavase a importância de uma participação ativa de todas as pessoas envolvidas na escola. 


\section{DISCUSSÃO}

Quanto à análise das entrevistas, constatou-se que o tema é bastante polêmico e discutível, podendo ser observada grande variedade de respostas e contradições entre as respostas de um mesmo entrevistado. A primeira ideia que pode ser discutida refere-se ao fato de a maioria dos professores, sobretudo na rede pública, sentirem que a prática da inclusão está muito distante do que é proposto teoricamente (categoria 1), apesar de os professores apontarem aspectos positivos do processo, avaliando a experiência como boa (categoria 12).

Um dos fatos que pode explicar a posição mais favorável dos professores das escolas particulares quanto à inclusão pode ser o maior contato dos docentes com o tema (categoria 8). Esse contato norteia a maneira como os professores trabalharão com os alunos, sendo que a maior dificuldade dos entrevistados se refere à falta de conhecimento sobre o assunto. Um dos maiores problemas do processo é a deficiência na formação, sendo que um preparo voltado para um olhar crítico e inovador é uma das estratégias mais enfatizadas em estudos (Pletsch, 2009).

A maioria dos professores apontou sentimentos ruins ao saber que lecionaria para alunos com NEE (categoria 2), o que pode estar relacionado à falta de preparo para lidar com a inclusão. Nas escolas particulares, a maioria dos professores apontou o estudo como forma de lidar melhor com o processo, o que pode ser reflexo da constante formação, indicando também a forma como esse fato é incentivado na escola. Já a escola pública pareceu não incentivar esse trabalho, indicando que o governo devia se responsabilizar por isso. Com relação às escolas particulares, pode-se pensar que a instabilidade do cargo pode fazer com que haja um melhor preparo para lidar com as situações difíceis, a fim de garantir o seu emprego.

Os entrevistados relataram que a educação dos alunos de inclusão poderia ser melhorada se os professores fossem mais bem preparados ou se fossem contratadas pessoas qualificadas para isso. Assim, reflete-se a forma como esse processo é conduzido nas escolas, uma vez que a escola particular procura incentivar o estudo dos professores, enquanto que a escola pública tem um desejo de que outras pessoas complementem o trabalho daqueles que já estão inseridos na escola. É digno de nota salientar, entretanto, que as condiçôes de trabalho são mais adversas na rede pública do que na particular, tanto em termos do número de alunos por turma quanto em termos do background sociocultural dos alunos atendidos. Além disso, embora existisse a percepção dos professores das escolas particulares de que a formação poderia auxiliar no processo, estes profissionais não deixaram de indicar que a escola especializada poderia trazer mais avanços aos alunos com NEE, o que indica a percepção de que o processo é falho. 
A falta de preparo dos professores foi refletida na maneira como as aulas e as avaliações eram conduzidas. Na escola pública, o aluno observado não realizava avaliações, de forma que recebia no boletim a mesma nota para todas as disciplinas, apenas de caráter simbólico. A aprendizagem do aluno e o processo de ensino desenvolvido não eram avaliados, o que poderia indicar importantes falhas do processo de inclusão. A forma de avaliar o aluno com base em uma concepção diagnóstica pode fazer com que a escola flexibilize o seu currículo, favorecendo a aprendizagem do aluno de inclusão, como relatam Machado et al., (2006).

Todos os entrevistados relataram ter verificado avanços entre os alunos com NEE (categoria 9). Apesar disso, na mesma categoria, verificaram-se ressalvas nos entrevistados das escolas particulares, cuja maioria relatou que a escola especializada poderia ter alcançado melhores resultados. Essa ideia pode ser um indicativo de que a escola percebia que o trabalho com esses alunos era limitado, o que se mostra contraditório com a opinião aparentemente mais favorável desses professores a respeito da inclusão escolar de alunos com NEE.

Os professores, sobretudo da escola pública, focam o trabalho no processo de socialização. O resultado obtido nesta pesquisa comprova o que constataram Oliveira e Miranda (2007), que relataram que os professores, muitas vezes, veem a socialização do aluno de inclusão como o único ponto positivo do processo. Porém, mesmo nesse aspecto da socialização, mais de um terço das respostas dos professores indicaram que os esses alunos tinham poucos amigos e sofriam preconceitos e exclusão, o que vai ao encontro da literatura revisada (Batista \& Enumo, 2004).

Deve-se pensar em estratégias de mudanças para que as escolas possam favorecer a aprendizagem e socialização desses alunos, uma vez que foi constatado que as escolas pareciam não ter se modificado, ou modificado pouco, para recebê-los (categoria 11). Quando a maioria dos entrevistados relatou que a escola não precisava de adaptaçóes para receber esses alunos, houve mais uma falta de reflexão sobre o tema do que a existência de condições adequadas para a inclusão.

Com relação à observação dos alunos em sala de aula, notou-se que a relação de Artur com os colegas de sala não ocorria de forma satisfatória. Já a interação do aluno com o acompanhante parecia ser muito boa, sendo que este fazia uso do que estava sendo ensinado pela professora para ajudar o aluno, o que favorece sua inclusão nas atividades escolares. Artur adquiriu confiança com a presença do auxiliar, o que também pôde contribuir para melhorar seu desempenho escolar. Entretanto a presença do acompanhante não exclui a importância do professor no processo, que é fundamental para que o aluno seja verdadeiramente incluído 
na sala de aula. Seria importante que o aluno tivesse a oportunidade de também tirar dúvidas com o professor, já que isso poderia fazer com que este percebesse quais as dificuldades e potencialidades de Artur.

Pôde-se perceber que a aprendizagem desse aluno vinha sendo trabalhada. No entanto, esse progresso devia ser visto mais como um meio fornecido pelos pais do que pela própria escola, pois estes financiavam o acompanhante, que era responsável por parte do trabalho que deveria ser realizado pela escola. Por outro lado, a presença do acompanhante poderia excluir o aluno e fazer com que este fosse visto como diferente da sala, dificultando a socialização. A escola devia pensar medidas para inseri-lo, visto que a socialização poderia facilitar a aprendizagem.

Quanto ao aluno Pedro, percebeu-se que a interação deste ocorria principalmente com os três alunos que se sentavam próximos. Esses alunos pareciam dispostos a ajudar Pedro e a conversar com ele, mas dificilmente eram eles que iniciavam a conversa. A relação de Pedro com os professores ocorria por meio de conversas entre eles durante a aula. Os professores não consideravam algumas afirmações que o aluno fazia a respeito do conteúdo, o que fez parecer que Pedro não tinha nada a acrescentar à classe. A inclusão desse aluno na escola vinha ocorrendo de forma deficitária, visto que as potencialidades do aluno poderiam ser trabalhadas e a interação entre ele e seus colegas também poderia ser facilitada com base em um novo projeto da escola.

É possível considerar que o aluno passava por um processo de segregação, visto que os professores e alunos chegavam a desconsiderar sua participação na sala de aula. Seria importante que os outros alunos fossem estimulados a se envolver em atividades com Pedro para ajudá-lo e conhecê-lo mais, favorecendo a socialização e aprendizagem entre todos (Pletsch, 2009). Seria preciso que houvesse outra forma de estruturação escolar, uma vez que o aluno se encontrava excluído do processo de ensino e de avaliação, não recebia materiais didáticos e não realizava provas.

Quanto a Iara, foi possível perceber que a relação da aluna com os outros colegas era satisfatória, e eles procuravam ajudá-la e motivá-la, o que era reforçado pela professora. A interação da professora com Iara parecia ocorrer bem, visto que ela procurava ajudar, elogiar e chamar a atenção da aluna, sem distinções com os outros alunos. As potencialidades dela nessa disciplina (Educação Física) estavam sendo trabalhadas, bem como as suas limitaçoes, como a dificuldade de permanecer na mesma atividade por muito tempo. Observou-se que havia momentos em que a aluna se distanciava do restante da sala, o que devia ser notado para evitar que ocorresse com frequência. 
A inclusão pôde ser apontada como um processo que vinha trazendo benefícios para a aluna, pois ela parecia ser respeitada pelos colegas e adquiriu conhecimentos. A interação da escola com os seus pais e a consciência de que estes tinham dos potenciais e dificuldades da filha podem ter contribuído para os seus avanços, o que demonstra a importância de sempre ocorrer um trabalho em conjunto entre a família e a escola. É preciso considerar, entretanto, que o fato das observações terem ocorrido em aulas de Ed. Física, disciplina que enfatiza habilidades diferentes daquelas mais acadêmicas, dificultou a generalização dos dados obtidos para outras áreas.

Sobre a análise realizada nos PPP das escolas A e C, notou-se que nenhuma delas trabalhava diretamente em seu planejamento o tema da inclusão escolar. É importante destacar que essa discussão, sobretudo se realizada entre os diferentes envolvidos com a educação, poderia favorecer que a inclusão alcançasse seus objetivos de forma mais satisfatória (Melo \& Martins, 2007). O fato de os PPP não abordarem o tema da inclusão confirmou o já apontado nas entrevistas: as escolas não se adaptaram para receber os alunos com NEE (Machado et al., 2006).

Dois pontos importantes foram abordados no PPP da escola C. O primeiro se referia à relevância da constante formação dos professores, com cursos extracurriculares, até mesmo oferecidos pela escola. Muitas vezes, o professor não tem acesso ao tema da inclusão escolar durante a sua graduação, o que fortalece ainda mais a importância dos cursos. $\mathrm{O}$ segundo ponto referia-se à importância da participação dos agentes de ensino, da comunidade e da família para incluir os diferentes alunos (Costa, 2011). A importância desse trabalho em conjunto é ressaltada na literatura e deve sempre ser pensada com relação à inclusão (Melo \& Martins, 2007).

\subsection{Discussão geral: uma relação entre os dados}

Pelo entrelaçamento dos dados obtidos, pôde-se perceber que as escolas estudadas apresentavam dificuldades com relação à condução do processo de inclusão escolar, sendo que cada uma parecia ter se adaptado para conviver com a realidade, embora essa adaptação não refletisse os objetivos da inclusão escolar e pouco favorecesse o aluno.

$\mathrm{Na}$ escola pública, percebeu-se que as dificuldades se refletiam na ausência de adaptação da escola e de busca ativa pelo conhecimento que poderia auxiliar os agentes da educação a lidar de uma melhor maneira com o tema. $\mathrm{O}$ aluno Pedro era excluído das atividades realizadas em sala de aula, o que prejudicava sua socialização e aprendizagem. A análise do PPP demonstrou que não houve adaptação física, de conteúdo e preparo da equipe para atender a esses alunos. 
Entre as escolas particulares, houve uma dificuldade em avaliar a forma como o projeto ocorria na escola B. Com base nas entrevistas, pôde-se perceber uma tentativa de auxiliar a aluna com NEE. No entanto, houve poucos elementos, além da fala dos professores, que poderiam complementar o discurso deles.

Com relação à escola $\mathrm{C}$, o incentivo ao estudo dos professores pareceu apresentar resultados, uma vez que a base teórica lhes possibilitava maior confiança e otimismo para lidar com a inclusão. Apesar de todo o preparo, é importante destacar que esses professores não deixaram de apontar para a escola especial como uma possibilidade que traria mais benefícios aos alunos. Assim, observa-se que ainda existiam lacunas no processo de inclusão, mesmo com a escola buscando alternativas para auxiliar esses alunos.

O maior contato com os pais dos alunos na escola $\mathrm{C}$ pode ser um ponto positivo, mas deve-se atentar para que os pais não sejam os únicos responsáveis pela inclusão dos filhos. É importante que os pais sejam próximos à escola para discutir e participar e não para tomar decisões ou assumir responsabilidades que seriam da equipe pedagógica.

Com relação ao aluno Artur, a escola parecia ter mais dificuldades, como a diferença de idade deste para o restante da sala. Para isso, seria interessante pensar maneiras de trabalhar o fato, por exemplo, por meio de atividades nas quais fossem discutidas as diferenças de idades e as diferentes experiências que cada aluno já viveu. Quanto ao acompanhante, seria interessante pensar em formas de possibilitar maior autonomia do aluno em relação a ele, uma vez que Artur adquiria conhecimentos, mas não se socializava. Essa estratégia da escola devia ser discutida e relativizada: a presença de um professor particular na sala de aula poderia ser vista como uma maneira de os pais do aluno financiarem a inclusão e se responsabilizarem pela aprendizagem do filho, o que segregava o aluno e tirava a responsabilidade da escola pelo processo.

De forma geral, os dados obtidos parecem indicar que lacunas na formação inicial e continuada dos docentes com relação ao tema da inclusão seriam um dos principais fatores responsáveis pelas dificuldades encontradas, contribuindo também para o menor grau de reflexão sobre as mudanças necessárias em diferentes aspectos da instituição escolar.

É preciso refletir que cada aluno de inclusão tem as suas limitações, que precisam ser trabalhadas de diferentes formas pela escola. A escola A precisaria se adaptar, em diferentes níveis, para receber o aluno Pedro, que tinha diversas limitações, enquanto que a aluna Iara (escola $\mathrm{C}$ ) parecia ter dificuldades menores, facilitando a adaptação da escola. Apesar disso, destaca-se que todas as escolas deveriam estar previamente adaptadas, em termos de estrutura física e adaptação curricular, para receber diferentes alunos, ajustando-se às suas dificuldades. 
Há a necessidade de considerar os diferentes fatores que influenciam no processo de inclusão escolar. O fato de terem sido observadas apenas três escolas dificulta a generalização dos resultados para outras instituições, mas possibilita a reflexão para estratégias de trabalho. Seria interessante que a discussão do tema se iniciasse na elaboração de um PPP voltado para a diversidade e que novas maneiras de atuação fossem definidas e praticadas (Silva, 2011).

A família e o Estado também têm responsabilidades para com o aluno. É pertinente sugerir que a família se aproxime da escola para que possa acreditar no trabalho desta e pensar em conjunto estratégias de ação, enquanto que o Estado deve promover ações práticas de apoio à escola, fornecendo os subsídios necessários e garantidos por lei para a efetivação do projeto (Oliveira et al., 2011). Tal apoio poderia consistir na disponibilização de recursos a serem empregados de acordo como as necessidades estabelecidas no PPP por cada unidade escolar.

\section{CONSIDERAÇÕES FINAIS}

Com base nesse trabalho, é possível entender que o processo de inclusão nessas três escolas encontra-se em fase de transição para um novo modelo de educação, o que gera tensão, dificuldades e a necessidade de se discutirem estratégias de aplicabilidade para que os objetivos sejam alcançados. É importante ressaltar que os dados não devem ser generalizados, ou seja, não é possível inferir que todas as escolas estão despreparadas para incluir os alunos de NEE.

Entende-se a importância da realização de outras pesquisas, para verificar como o processo está sendo aplicado e desenvolvido, para refletir sobre as dificuldades encontradas e possíveis formas de superá-las, garantindo a todos uma escola inclusiva de qualidade. 


\section{Referências}

Aranha, M. S. F. (2001). Paradigmas da relação da sociedade com as pessoas com deficiência. Revista do Ministério Público do Trabalho, 11(21), 160-173.

Batista, M. W. \& Enumo, S. R. F. (2004). Inclusão escolar e deficiência mental: análise da interação social entre companheiros. Estudos de Psicologia, 9(1), 101-111.

Bogdan, R. \& Biklen, S. (2000). Investigação qualitativa em educação. Porto: Editora Porto.

Costa, S. M. L. (2011). Adaptação curricular na escola inclusiva e seus reflexos no processo de aprendizagem e socialização dos alunos com necessidades educativas especiais (Monografia de Especialização). Universidade de Brasília, Programa de Pós-Graduação em Processos de Desenvolvimento Humano e Saúde, Brasília.

Fiório, F. B. \& Almeida, S. M. A. (2013). Concepção dos docentes acerca da inclusão de alunos com deficiência na Unochapecó. FisiSenectus, 1, 139.

Lei no 9.393, de 20 de dezembro de 1996. (1996, 20 dezembro). Lei de Diretrizes e Bases de Educação Nacional. Diário Oficial da Uniāo, Brasília.

Machado, K., Fontes, R., Assumpção, V. de, \& Glat, R. (2006). Cotidiano escolar: desafios didáticos e pedagógicos no processo de inclusão educacional. In Anais, do 13 Encontro Nacional de Didática e Prática de Ensino (pp. 1-14), Recife. [CD-ROM].

Melo, F. R. L. V. \& Martins, L. de A. R. (2007). Acolhendo e atuando com alunos que apresentam paralisia cerebral na classe regular: a organização da escola. Revista Brasileira de Educação Especial, 13(1), 111-130.

Oliveira, A. K. de S., Santos, G. C. N. dos, Rodrigues, M., \& Viana, N. F. (2011). Gestão, coordenação e orientação educacional. Revista Pesquisa e Criação, 10(1), 51-66. Recuperado a partir de http://www.periodicos.unir.br/ index.php/propesq/article/view/394/416

Oliveira, M. C. \& Miranda, A. A. B. (2007). Inclusão escolar: concepções de professores de alunos deficientes mentais na educação regular. Revista Eletrônica Horizonte Cientifico, 1(7), 1-22. Recuperado a partir de http://www.seer.ufu. br/index.php/horizontecientifico/article/view/3843/2848 
Pletsch, M. D. (2009). A formação de professores para a educação inclusiva: legislação, diretrizes, políticas e resultados de pesquisas. Educar, 33, 143-156.

Silva, A. F. (2011). Inclusão escolar: desafios e perspectivas de implementação do Projeto Político Pedagógico na escola. (Monografia de Graduação). Universidade de Brasília, Faculdade de Educação, Brasília.

Silva, A. N. C. (2013). O direito à acessibilidade e a inclusão escolar: um estudo de caso de uma escola pública do Distrito Federal. (Monografia de Graduação). Universidade de Brasília, Faculdade de Educação, Brasília.

UNESCO (1994). Declaração de Salamanca: sobre princípios, políticas e práticas na área das necessidades educativas especiais. Lisboa: IIE.

Vianna, P. B. M., Gomes, J. T., \& Garcia, K. B. A. (2013). Educação inclusiva: espaço físico, prática pedagógica e perspectiva da gestão da educação inclusiva. Revista Educação em Rede, 2(2), 50-62. 